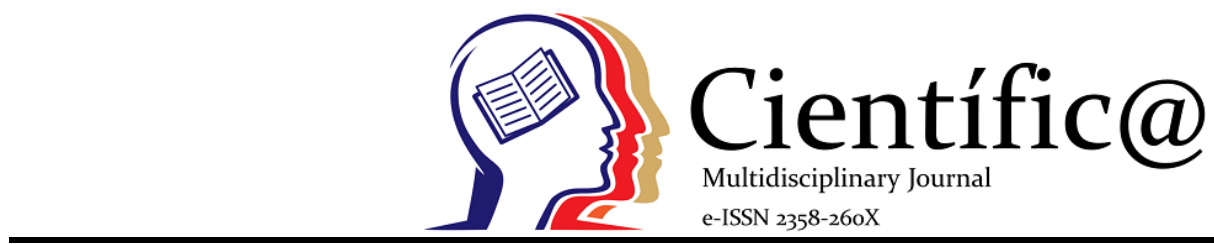

\title{
FONTES E DOSES FOSFATADAS EM CULTIVO DA CULTURA DA SOJA NO CERRADO E SUAS RESPOSTAS À FERTILIDADE DO SOLO
}

\section{PHOSPHATE SOURCES AND DOSES IN SOYBEAN CROP CULTIVATION IN THE CERRADO AND THEIR RESPONSES TO SOIL FERTILITY}

\author{
José Mateus Kondo Santini*1; Salatiér Buzetti2; Adriano Perin³; Carlos Frederico de Souza \\ Castro4; Leonnardo Cruvinel Furquim ${ }^{5}$; Daniel Noe Coaguila Nunez ${ }^{6}$; Flávio de Oliveira \\ Silveira7; Luiz César Lopes Filho8; Anderson Cruvinel Cabral ${ }^{9}$
}

\footnotetext{
${ }^{1}$ Autor para correspondência; Engenheiro Agrônomo, Dr., Professor do Instituto de Ensino Superior de Rio Verde santini@faculdadeobjetivo.com.br*;

${ }^{2}$ Engenheiro Agrônomo, Dr., Professor da Universidade Estadual Paulista - Faculdade de Engenharia de Ilha Solteirasbuzetti@agr.feis.unesp.br.

${ }^{3}$ Engenheiro Agrônomo, Dr., Professor do Instituto Federal Goiano - Câmpus Rio Verde-perinrj@yahoo.com.br;

${ }^{4}$ Químico, Dr., Professor do Instituto Federal Goiano - Câmpus Rio Verde-carlosfscastro@gmail.com;

${ }^{5}$ Engenheiro Agrônomo, Me. Professor do Instituto de Ensino Superior de Rio Verde-

leonnardo.cruvinel@faculdadeobjetivo.com.br;

${ }^{6}$ Biólogo, Dr. Professor do Instituto de Ensino Superior de Rio Verde-tuheraldo@gmail.com;

${ }^{7}$ Engenheiro Agrônomo, Consultor técnico da empresa Exacta-exacta.ai@gmail.com;

${ }^{8}$ Engenheiro Agrônomo Me. Professor do Instituto de Ensino Superior de Rio Verde-lopesfilholuizcesar@gmail.com;

${ }^{9}$ Acadêmico do curso de Engenharia agronômica do Instituto de Ensino Superior de Rio Verdeandersoncruvinelrv@gmail.com.
}

Info

Recebido: 21/06/2019

Publicado: $10 / 02 / 2020$

DOI: $10.29247 / 2358-260 X .2019 v 6 i 2 . p 24-29$

ISSN: 2358-260X

Palavras-Chave
Adubos, fertilidade do solo, Glycine $\max ($ (L.)
Merrill.
Keywords:
Fertilizers, soil fertility, Glycine $\max$ (L.)

\section{Resumo}

A cultura da soja é uma das principais culturas do agronegócio brasileiro, podendo ser limitada por adubações equivocadas em área de cerrado. Com o presente trabalho, objetivou avaliar a dinâmica da adubação fosfatada, pelo uso de fontes e doses na adubação de manutenção da cultura da soja, em solo com alto teor de $\mathrm{P}$, verificando a real eficácia do uso do superfosfato triplo de eficiência aumentada. 0 experimento foi realizado em delineamento em blocos ao acaso, com quatro repetições, em esquema fatorial de $2 \times 5$, sendo o primeiro fator fontes de fertilizantes (superfosfato triplo e superfosfato triplo de eficiência aumentada) e segundo fator doses de $\mathrm{P}_{2} \mathrm{O}_{5}$ $\left(0,40,80,120\right.$ e $\left.240 \mathrm{~kg} \mathrm{ha}^{-1}\right)$. 0 experimento foi conduzido em área experimental, em Rio Verde, GO, buscando-se avaliar as influências nas características de componentes de produção e produtividade da soja, bem como, na dinâmica do P no solo. Constatou-se que a cultura da soja não respondeu à adubação fosfatada, em solo com alto teor de P. 0 uso do Superfosfato triplo de eficiência aumentada não modifica a produtividade de grãos, mas, aumentou a exportação de P via grãos da cultura, em comparação ao Superfosfato Triplo convencional. Para a adubação fosfatada, recomenda-se o uso do Superfosfato triplo convencional na dose de $75 \mathrm{~kg} \mathrm{ha}^{-1} \mathrm{de}_{2} \mathrm{O}_{5}$.

\footnotetext{
Abstract

The soybean crop is of the main crops of Brazilian agribusiness, and may be limited by wrong fertilization in cerrado. With this study aimed to evaluate the dynamics of phosphate fertilizer, the use of fertilization sources and doses in soybean maintenance, on soil with high content of $\mathrm{P}$, and checking the actual effectiveness of the use of triple superphosphate increased efficiency. The experiment was conducted in completely randomized block design with four replications in a factorial scheme $2 \times 5$, being the first factor sources of fertilizers (triple superphosphate and triple increased efficiency superphosphate) and second factor five doses of $\mathrm{P}_{2} \mathrm{O}_{5}(0,40,80$, 120 and $240 \mathrm{~kg} \mathrm{ha}^{-1}$ ). The experiment was conducted at the experimental area in Rio Verde, GO, seeking to evaluate the influences on the characteristics of production components and soybean yields, soil fertility, nutrient concentrations of harvested soybeans and the dynamics of $\mathrm{P}$ in the soil. For phosphate fertilizer, it is recommended the use of conventional triple superphosphate at dose of $75 \mathrm{~kg} \mathrm{ha}^{-1}$ of $\mathrm{P}_{2} \mathrm{O}_{5}$.
} 


\section{INTRODUÇÃO}

O Brasil e os Estados Unidos são os maiores produtores de Soja (Glycine max (L.) Merrill) do mundo. $\mathrm{Na}$ agricultura brasileira a cultura é um dos principais produtos produzidos e exportados. Somente essa cultura, na safra 2018/2019, atingiu a produtividade de 114,843 milhões de toneladas, com 35,822 milhões de hectares ocupados, com produtividade de grãos atingindo a marca de $3.206 \mathrm{~kg} \mathrm{ha}^{-1}$ (CONAB, 2019).

Dentre os nutrientes requeridos pelas plantas o fósforo $(\mathrm{P})$ é meritório de destaque por estar presente na fotossíntese, com a produção de ATP, crescimento e divisão celular, sendo indispensável para que a cultura complete seu ciclo.

Visando a máxima produtividade da cultura, o suprimento do nutriente em quantidades adequada, para o melhor desenvolvimento da cultura, é indispensável. Sendo a adubação a forma mais fácil de trabalhar o fornecimento do nutriente. As cultivares de soja, podem apresentar maior deficiência do nutriente, em solos tropicais, por conta da alta adsorção do $\mathrm{P}$ ao ferro e alumínio, reduzindo a disponibilidade do P em forma assimilável pela cultura (MACHADO, V. J. et al., 2011).

Uma alternativa para aumentar a eficiência das adubações fosfatadas é o uso de fontes de fertilizantes de eficiência aumentada. Sendo nestes fertilizantes, os nutrientes disponibilizados de forma gradual e de acordo com a necessidade da cultura. $\mathrm{O}$ uso desses fertilizantes visa a redução da adsorção de P no solo, aumentando a eficiência da adubação, tendo como resultado uma redução na aplicação do nutriente (ZAHRANI, 2000), uma vez que as fontes fosfatadas é um insumo de alto valor e de fonte não renovável.

Com o presente trabalho objetivou-se avaliar a influência de fontes e doses de fósforo, cultivada em solos com teor alto de $\mathrm{P}$, nas concentrações de nutrientes nos tecidos vegetais das grãs de soja.

\section{MATERIAL E MÉTODOS}

$\mathrm{O}$ experimento foi conduzido à campo no município de Rio Verde, GO, com localização geográfica entre os paralelos $20^{\circ} 45^{\prime}$ de latitude sul e $51^{\circ}$ 55 ' de longitude oeste, com altitude de $748 \mathrm{~m}$. A caracterização físico-química apresentou os seguintes valores: $\mathrm{pH}$ (em água) $=5,6 ; \mathrm{MO}=35,0 \mathrm{~g} \mathrm{dm}^{-3} ; \mathrm{P}$ $\left(\right.$ Mehlich I) $=41,0 \mathrm{mg} \mathrm{dm}^{-3} ; \mathrm{K}=6,7 \mathrm{mmol}_{\mathrm{c}} \mathrm{dm}^{-3} ; \mathrm{Ca}=$ $37,8 \mathrm{mmol}_{\mathrm{c}} \mathrm{dm}^{-3} ; \mathrm{Mg}=17,3 \mathrm{mmol}_{\mathrm{c}} \mathrm{dm}^{-3} ; \mathrm{S}=3,1 \mathrm{mg}$ $\mathrm{dm}^{-3} ; \mathrm{Al}=0,0 \mathrm{mmol}_{\mathrm{c}} \mathrm{dm}^{-3} ; \mathrm{V}=53,9 \%$ e textura média (333 $\mathrm{g} \mathrm{kg}^{-1}$ de argila, $166 \mathrm{~g} \mathrm{~kg}^{-1}$ de silte e $501 \mathrm{~g} \mathrm{~kg}^{-1} \mathrm{de}$ areia).

A precipitação pluvial acumulada mensal durante o experimento foi de: outubro (2011): $232 \mathrm{~mm}$; novembro (2011): $76 \mathrm{~mm}$; dezembro (2011): $165 \mathrm{~mm}$; janeiro (2012): $275 \mathrm{~mm}$; fevereiro (2012): $265 \mathrm{~mm}$; março (2012): $125 \mathrm{~mm}$.

O experimento foi conduzido em delineamento em blocos ao acaso, com quatro repetições, em esquema fatorial de $2 \times 5$. O primeiro fator foi constituído de fontes de fertilizantes (superfosfato triplo e superfosfato triplo de eficiência aumentada) e o segundo fator doses de aplicação $(0,40$, 80,120 e $240 \mathrm{~kg} \mathrm{P}_{2} \mathrm{O}_{5} \mathrm{ha}^{-1}$ ) de fertilizantes fosfatados na semeadura.

Antecedendo a semeadura do experimento realizou-se a dessecação da área, em 21/10/2011, utilizando herbicida glyphosate, na dose de $960 \mathrm{~g}$ i.a ha 1. As sementes do cultivar de soja NA 7337 RR foram tratadas com Imidacloprid e Thiamethoxam, ambos na dosagem de $105 \mathrm{~g}$ i.a para cada $100 \mathrm{~kg}$ de sementes de soja. Posteriormente, foi realizada a inoculação da soja com Bradyrbizobium japonicum na dosagem de 200 gramas de inoculante (turfa moída) para $40 \mathrm{~kg}$ de sementes, sendo considerada a concentração mínima de $10^{8}$ células viáveis por grama de turfa. Simultaneamente à 
semeadura foram aplicados $100 \mathrm{~kg} \mathrm{~K}_{2} \mathrm{O} \mathrm{ha-1}$ de, na forma de $\mathrm{KCl}$, e $\mathrm{P}_{2} \mathrm{O}_{5}$ de acordo com cada tratamento.

Cada unidade experimental foi composta por cinco linhas, espaçadas entre si $0,45 \mathrm{~m}$, com cinco metros de comprimento. Considerou-se como área útil da parcela as três fileiras centrais e desprezou-se $0,5 \mathrm{~m}$ das extremidades, totalizanto $5,4 \mathrm{~m}^{2}$. A semeadura foi realizada em 29/10/2011, distribuindo-se 18 sementes por metro no sulco de semeadura, utilizando a semeadora-adubadora.

O controle de plantas daninhas em pósemergência foi realizado com o uso do herbicida glyphosate, na dose de $960 \mathrm{~g}$ i.a ha-1 aos 15 e 40 dias após a emergência (DAE). Também foi realizado o controle da lagarta da soja (Anticarsia gemmatalis) e lagarta falsamedideira (Pseudoplusia includens) aos 45 DAE com Teflubenzurom (50 mL ha-1). A partir dos 60 DAE, procurou-se identificar focos de ferrugem asiática, neste período, foi aplicado o fungicida trifoxystrobin + ciproconazole $\left(300 \mathrm{~mL} \mathrm{ha}^{-1}\right)$, preventivamente, uma vez que a doença não foi encontrada. Doze dias após a primeira aplicação preventiva para controle de ferrugem asiática, outra amostragem foi realizada no experimento e constatado o foco da doença, efetuou-se então, o controle com o fungicida azoxystrobin + ciproconazole $(300 \mathrm{~mL}$ $\mathrm{ha}^{-1}$ ), realizando essa mesma prática aos $85 \mathrm{DAE}$.

Foram realizadas as avaliações de concentração de nutrientes nos tecidos vegetais dos grãos. Para isso, o material foi coletado manualmente e, com o auxílio de uma trilhadora mecânica, o material foi trilhado, antes da trilha o material permaneceu em estufa de ventilação forçada $\left(\mathrm{em} 65^{\circ} \mathrm{C}\right)$ até massa constante.

$\mathrm{Na}$ análise de concentração nutricional nos grãos, nas amostras devidamente secas, em estufa, e moídas, com moinho do tipo Wiley, efetuaram-se as análises nutricionais de $\mathrm{N}, \mathrm{P}, \mathrm{K}, \mathrm{Ca}, \mathrm{Mg}, \mathrm{S}, \mathrm{B}$, $\mathrm{Cu}, \mathrm{Fe}, \mathrm{Mn}$ e Zn, utilizando a metodologia descrita por Malavolta et al. (1997).
Para a comparação de médias dos tratamentos, inicialmente, realizou-se o teste de Kolmogorov - Smirnov, buscando avaliar a homocedasticidade (5\%) das variáveis, nos casos em que o $\mathrm{H}_{0}$ foi rejeitado, efetuou a transformação de dados utilizando a equação $(x+0,5)^{0,5}$. Posteriormente, os dados foram submetidos à análise de variância utilizando o pacote ExpDes do software R 3.2.2 programa estatístico R (Ferreira et al., 2011). Quando verificado efeito significativo para as variáveis qualitativas, foi realizada a comparação de médias pelo teste de Tukey $(\mathrm{p}<$ 0,05), já para as variáveis quantitativas foram realizadas regressões polinomiais (de primeiro e segundo grau) à 5\% e 1\% de probabilidade.

\section{RESULTADOS E DISCUSSÃO}

As concentrações nutricionais nos grãos de soja não foram influenciadas pelas fontes fosfatadas avaliadas. Não obstante, não houve interação significativa entre as fontes e doses avaliadas nas concentrações nutricionais. Já para as doses, houve ajustes para as concentrações de $\mathrm{N}$ (quadrático; p < 0,05) e para o Fe (linear; p $<0,05$ ), não verificando maior parte de ajustes, nas demais concentrações nutricionais nos grãos de soja $(\mathrm{P}, \mathrm{K}, \mathrm{Ca}, \mathrm{Mg}, \mathrm{S}, \mathrm{B}, \mathrm{Cu}$, Mn e Zn; Tabela 1).

Os poucos efeitos verificados para as variáveis de concentração de nutrientes nos grãos de soja (Tabela 1), são explicados devido a expressão fenotípica na cultura ser relativamente estável, ou seja, se pressupõe que as características sejam controladas por poucos genes (Buratto, 2012), assim, a soja em condições adequadas, tendem a manter estáveis as concentrações nutricionais, sem muitas variações. Entretanto, alguns nutrientes são controlados por maior número de genes, como do Fe, possuindo alta variação, característica de herança mais complexas (Buratto, 2012), o que pode ter 
levado ao aumento na concentração de Fe no presente

trabalho.

Tabela 1. Concentração Média, desvio padrão amostral (s), coeficiente de variação (CV) e teste F; de N, P, K, Ca, $\mathrm{Mg}, \mathrm{S}, \mathrm{B}, \mathrm{Cu}, \mathrm{Fe}, \mathrm{Mn}$ e Zn, em grãos colhidos de soja, influenciados por fontes (Superfosfato triplo convencional; Superfosfato triplo revestido por polímeros) e doses $\left(0 ; 40 ; 80 ; 120\right.$; e $\left.240 \mathrm{~kg} \mathrm{P}_{2} \mathrm{O}_{5} \mathrm{ha}^{-1}\right)$ de aplicação fosfatada, em sulco de semeadura, de fertilizantes fosfatados.

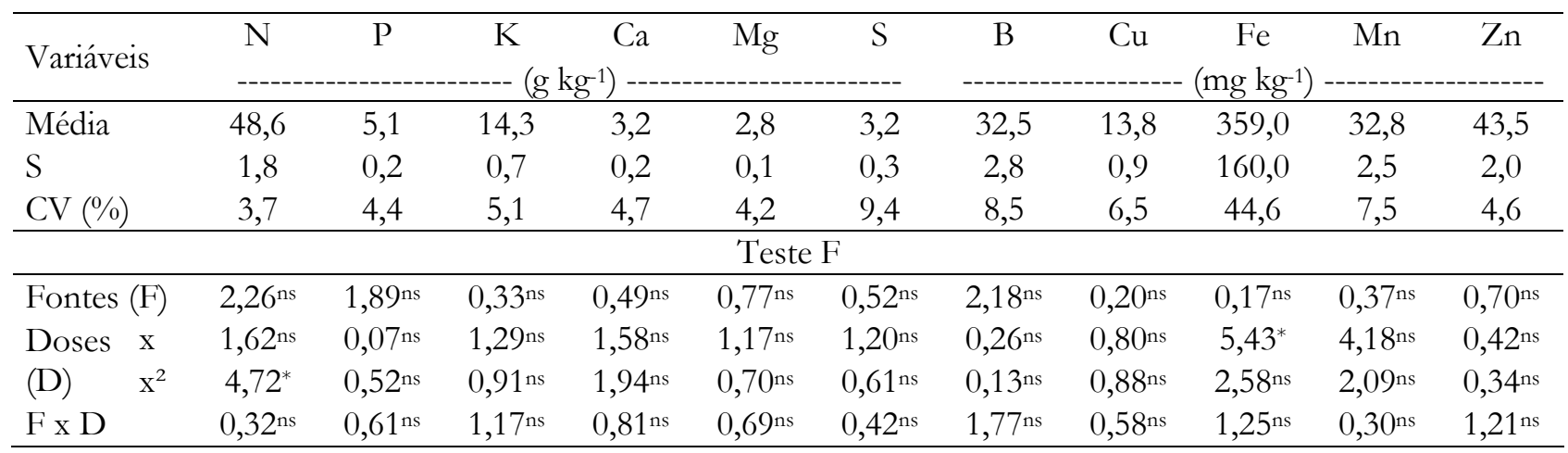

ns: Não significativo; *: Significativo a 5\%.

Os resultados significativos para as doses, já supracitados, encontram-se dispostos na Tabela 2. $\mathrm{Na}$ concentração de nutrientes nos grãos, o $\mathrm{N}$ ajustou de modo quadrático, com teor máximo de 49,2 $\mathrm{g} \mathrm{kg}^{-1}$ de $\mathrm{N}$, na dose de 109,5 kg de $\mathrm{P}_{2} \mathrm{O}_{5} \mathrm{ha}^{-1}$, quando valorado, ha- $\mathrm{de}_{2} \mathrm{P}_{5}$.

este acréscimo, tem como resultante aumento de 5,1\%,

Tabela 2. Concentração de $\mathrm{N}$ e Fe, nos grãos colhidos de soja, submetidos às doses $\left(0 ; 40 ; 80 ; 120\right.$; e $240 \mathrm{~kg} \mathrm{ha}^{-1}$ de $\left.\mathrm{P}_{2} \mathrm{O}_{5}\right)$ de adubação fosfatada, com seus respectivos ajustes e coeficiente de determinação $\left(\mathrm{R}^{2}\right)$.

\begin{tabular}{|c|c|c|c|c|c|c|c|c|c|}
\hline \multirow{2}{*}{\multicolumn{3}{|c|}{ Variáveis }} & \multicolumn{5}{|c|}{ Doses $\left(k g \mathrm{P}_{2} \mathrm{O}_{5} \mathrm{ha}^{-1}\right)$} & \multirow{2}{*}{ Ajuste } & \multirow{2}{*}{$\mathrm{R}^{2}$} \\
\hline & & & 0 & 40 & 80 & 120 & 240 & & \\
\hline \multirow{2}{*}{ Grãos } & $\mathrm{N}$ & $\left(\mathrm{g} \mathrm{kg}^{-1}\right)$ & 47,4 & 47,1 & 50,0 & 50,1 & 48,5 & $\begin{array}{c}\mathrm{N}=-0,0002 \mathrm{P}^{2}+0,0438 \mathrm{P}+ \\
46,82\end{array}$ & 0,6992 \\
\hline & $\mathrm{Fe}$ & $\left(\mathrm{mg} \mathrm{kg}^{-1}\right)$ & 197,0 & 437,3 & 330,0 & 334,0 & 497,0 & $\mathrm{Fe}=0,9111 \mathrm{P}+271,58$ & 0,5325 \\
\hline
\end{tabular}

$\mathrm{O}$ ajuste para as concentrações de $\mathrm{N}$ em relação as doses testadas, nos grãos de soja (Tabela 1), é explicado por Marschner (1995), onde o autor cita que o P tem função primordial na FBN, inferindo diretamente à produção e consumo de ATP, dessa forma o aumento do $\mathrm{P}$ ao solo, pode ter resultado na maior nodulação, refletindo no acréscimo de $\mathrm{N}$ na soja.
É possível que devido a fertilidade do solo estar adequada, o uso das fontes não influenciou, de sobremaneira, as concentrações de nutrientes nos tecidos de grãos. Porém, torna-se conciso destacar a existência de divergência na real eficácia das tecnologias de fertilizantes de eficiência aumentada.

$\mathrm{Na}$ literatura, encontra-se trabalhos com efeitos benéficos ao uso desses fertilizantes (eficiência 
aumentada) como observado por Figueiredo et al., 2012; Santini et al., 2013; e Souza et al., 2014, mas, também, há trabalhos com resultados semelhantes do presente trabalho, sem diferenciação das fontes fosfatadas, a exemplo, os trabalhos de Valderrama et al., 2009; Valderrama et al., 2011; e Gazola et al., 2013.

Diante o exposto, acredita-se que os não efeitos, tanto para as doses, quanto para as fontes de fertilizantes é intrinsicamente explicada por Buratto (2012), como já mencionado, a expressão fenotípica na cultura da soja é estável, ou seja, as características são controladas por poucos genes. Sempre que a cultura estiver em condições adequadas (como no presente trabalho, em solo de alta fertilidade), tende a manter estáveis as concentrações nutricionais, sem muitas variações.

\section{CONCLUSÃO}

O Superfosfato triplo convencional é a melhor opção de aplicação, comparativamente ao superfosfato triplo de eficiência aumentada, devido a não diferença entre as fontes e ao fato do fertilizante convencional possuir melhor relação custo-benefício.

A adição de $\mathrm{P}$ no solo, via fertilizante, promoveu melhorias nas concentrações de $\mathrm{N}$ e Fe dos grãos de soja colhido.

\section{REFERÊNCIAS}

Buratto JS. Teores de minerais e proteina em grãos de feijão e estimativa de parâmetros genéticos. 147f. Tese (Doutorado) - Lavras : Universidade Federal de Lavras; 2012.

CONAB - Companhia Nacional de Abastecimento. Acompanhamento da Safra Brasileira: Grãos. Safra 2018/19 - Nono levantamento. Brasília, V.6, N.9, 113p.; 2019.
Duncan RR, Baligar VC. Genetics, breeding, and physiological mechanisms of nutrient uptake and use efficiency: An overview. In: BALIGAR VC, DUNCAN RR (eds). Crops as enhancers of nutrient use. Academic Press, Nova York, Estados unidos. 588 p.; 1990.

Ferreira DF.Sisvar: a computer statistical analysis system. Ciência e Agrotecnologia. 2011; 35(6):10391042.

Figueiredo CC, Barbosa DV, Oliveira AS, Fagioli M, Sato JH. Adubo fosfatado revestido com polímero e calagem na produção e parâmetros morfológicos de milho. Revista Ciência Agronômica. 2012; 43(3):446-452.

Gazola RN, Buzetti S, Dinalli RP, Teixeira Filho MCM, Celestrino TS. Efeito residual da aplicação de fosfato monoamônio revestido por diferentes polímeros na cultura de milho. Revista Ceres. 2013; 60(6):876-884.

Machado, V. J. et al. Curvas de disponibilidade de fósforo em solos com diferentes texturas após aplicação de doses crescentes de fosfato monoamônico. Bioscience Journal, Uberlândia, v. 27, n. 1, p. 70-76, 2011.

Malavolta E, Vitti GC, Oliveira AS. Fundações. In: Malavolta E, Vitti GC, Oliveira SA (Ed.). Avaliação do estado nutricional das plantas: princípios e aplicações. 2 ed.: Associação Brasileira para a Pesquisa da Potassa e do Fosfato, Piracicaba, Brasil. 319 p.; 1997.

Marschner H. Nitrogen fixation. In: Marschner H. (ed.) Mineral nutrition of higher plants. 2 ed. Academic Press, Londres, Inglaterra, 201-228p.; 1995. 
Santini JMK, Perin A, Silveira FO, Lopes Filho LC, Valderram M. The usage of NPK coated by polymers on the cotton crop (GOSSYPIUM HIRSUTUM L.) For biomass production on the aerial part. Global Science and Technology. 2013; 6(3):79-89.

Souza JR, Ribeiro BN, Raposo TP, Fiorin JE, Castro GSA, Magalhães RS. Eficiência do fósforo revestido com polímeros na cultura da soja $A$ cta Iguazu. 2014; 3(4):1-9

Valderrama M, Buzetti S, Benett CGS, Andreotti M, Alf $\mathrm{O}$, Eustaquio SM. Fontes e doses de nitrogênio e fósforo em feijoeiro no sistema plantio direto Pesquisa Agropecuária Tropical. 2009; 39(3):191196.

Valderrama M, Buzetti S, Benett CGS, Andreotti M, Teixeira Filho MCM. Fontes e doses de NPK em milho irrigado sob plantio direto Pesquisa Agropecuária Tropical. 2011; 41:(2):254-263.

Zahrani, S. Utilization of polyethylene and paraffin waxes as controlled delivery systems for different fertilizers. Industrial \& Engineering Chemistry Research, Washington, v.39, n.3, p.367-371, 2000. 